TAP CHÍ KHOA HOC ĐẠI HỌC TÂN TRÀO
ISSN: 2354 - 1431

\title{
TUYÊN QUANG VỚI VIỆC TẠO ĐIỀU KIỆN CƠ SỞ VẬT CHẤT, ĐẢM BẢO AN NINH CHO ĐOÀN ĐẠI BIỂU CÁCH MẠNG LÀO HOẠT ĐỘNG TẠI XÃ MĨ BẰNG (HUYỆN YÊN SƠN) TỪ NĂM 1950 - 1952.
}

\author{
Hoàng Thị Thu Dung ${ }^{1 *}$ \\ ${ }^{1}$ Đại học Tân Trào \\ *Email: hoangthithudung@gmail.com
}

\section{Thông tin bài viết}

Ngày nhận bài:

$15 / 7 / 2020$

Ngày duyệt đăng:

20/9/2020

Từ khóa:

Tuyên Quang, Kháng

chiến chống Pháp, Căn cứ

cách mang.

\section{Tóm tắt}

Tuyên Quang là một tỉnh thuộc khu vục miền núi phía Bắc Việt Nam, giáp với các tỉnh Thái Nguyên, Phú Thọ, Vĩnh Phúc, Yên Bái. Trong lịch sủ dụng nước và giũ nước của dân tộc Việt Nam, Tuyên Quang luôn được coi là vùng đất có vị trí chiến lược quan trọng về chính trị, kinh tế, quốc phòng, an ninh. Trong cuộc kháng chiến chống thục dân Pháp, Tuyên Quang trở thành căn cú cách mạng chính yếu của Đảng, ngoài ra cũng là nơi bảo vệ an toàn cho đoàn đại biểu cách mạng Lào trong thời gian sống và hoạt động tại Việt Nam.

\section{Mở đầu}

Tuyên Quang, với địa hình hiểm trở, núi rừng trùng trùng điệp điệp chiếm đến $73,3 \%$ diện tích toàn tỉnh. Về phía Tây Bắc có nhiều ngọn núi cao trên $1000 \mathrm{~m}$, phía đông nối liền với dãy Tam Đảo, dãy núi Thanh Sơn... Tất cả các rãy núi ấy tạo nên địa thế hiểm trở cho vùng đất này. Với địa thế như vậy, mảnh đất này từng được coi là "Trấn biên" che chở cho vùng đất "Kinh trấn". Tấm bia đá trên núi Thổ Sơn có ghi:

“An biên viễn hải ưu kim bạc

Tuyên Thành vạn cổ án Thăng Long”,

Dịch nghĩa:

"Vùng an biên xa biển có nhiều vàng bạc

Thành Tuyên Quang đời đời che chắn cho Thăng Long”
Nơi đây là địa bàn cư trú của nhiều dân tộc anh em. Từ buổi sơ khai, mảnh đất này đã có người nguyên thuỷ sinh sống. Đây cũng là vùng đất có bề dầy văn hóa, lịch sử, cách mạng. Tuyên Quang là nơi Bác Hồ và các đồng chí lãnh đạo cao cấp của Đảng đã sống và hoạt động cách mạng trong thời tiền khởi nghĩa. Trong cách mạnh tháng Tám năm 1945, Tuyên Quang có vị trí, vai trò vô cùng trọng đại. Tại xã Tân Trào, huyện Sơn Dương đã diễn ra nhiều sự kiện lịch sử quan trọng quyết định đến thời cơ và vận mệnh của dân tộc. Hội nghị toàn quốc của đảng từ ngày 13 đến ngày 15 tháng 8 năm 1945 đã quyết định phát động toàn dân tổng khởi nghĩa. Tiếp đó trong hai ngày 16 và 17 tháng 8 năm 1945, Quốc dân đại hội được triệu tập. Đại hội đã quyết định nhiều vấn đề trọng đại của đất nước.

Với vị trí quan trọng, hiểm yếu, nhưng cũng hết sức thuận lợi, xã Mỹ Bằng, huyện Yên Sơn, tỉnh 
Tuyên Quang đã được Đảng, Chính phủ chọn làm địa bàn hoạt động của đoàn đại biểu cách mạng Lào trong thời gian sông và hoạt động tại Tuyên Quang từ năm 1950 đến năm 1952.

\section{Nội dung}

Việt Nam và Lào là hai nước láng giềng có những nét tương đồng về văn hóa, vốn có quan hệ gần gũi lâu đời. Sự gần gũi về lịch sử phát triển và lịch sử văn hóa cùng sự tương đồng về việc lựa chọn con đường phát triển trong đấu tranh giải phóng dân tộc cũng như trong xây dựng đất nước trở thành một trong những nhân tố mang ý nghĩa quyết định tạo lập mối quan hệ hữu nghị đặc biệt Việt - Lào. Ngay từ sớm, Đảng ta và Hồ Chủ Tịch đã xác định tình đoàn kết và liên minh chiến đấu Việt Nam - Lào có vai trò đặc biệt đối với cuộc cách mạng ở mỗi nước.Tình hữu nghị, đoàn kết giữa hai Đảng, Chính phủ hai nước Việt Nam - Lào và sự gắn bó thủy chung, keo sơn giữa dân tộc Việt Nam và nhân dân các bộ tộc Lào được Chủ tịch Hồ Chí Minh và Chủ tịch Cayxỏn Phôm-vi-hản trực tiếp gây dựng nền móng, được các thế hệ lãnh đạo kế tục của hai Đảng, nhân dân hai nước quý trọng, nâng niu và dày công vun đắp.

Trong quá trình đấu tranh giải phóng dân tộc trước năm 1946, nhân dân hai nước Việt Nam - Lào đã nương tựa vào nhau, dưới sự lãnh đạo của Đảng Cộng sản Đông Dương, cùng chiến đấu chống lại ách thống trị của thực dân, phát xít. Sự đoàn kết của nhân dân hai nước đã đem lại kết quả rõ rệt khi cả Việt Nam và Lào đều giành thắng lợi, tuyên bố độc lập gần như đồng thời (Chính phủ Việt Nam Dân chủ Cộng hòa ra đời ngày 2 tháng 9 năm 1945, còn Chính phủ Lào Ítxala ra đời ngày 12 tháng 10 năm 1945).

Ngay sau khi được thành lập, hai nhà nước, hai chính quyền mới đã có những hoạt động chính trị để củng cố, nâng tầm quan hệ Việt - Lào. Ngày 16 tháng 10 năm 1945, Chính phủ hai nước đã kí kết Hiệp ước tương trợ Lào - Việt, và đến ngày 30 tháng 10 năm 1945, Hiệp định về tổ chức Liên quân Lào Việt cũng được kí kết. Với hai hiệp định này, mối quan hệ Việt - Lào không còn là mối quan hệ truyền thống giữa nhân dân hai nước, mà đã trở thành mối quan hệ có tính pháp lý - quan hệ giữa hai nhà nước độc lập vừa mới hình thành. Sự kiện này giúp thúc đẩy hơn nữa tình đoàn kết chiến đấu của nhân dân hai nước trong quá trình thực hiện những nhiệm vụ còn lại của cuộc cách mạng dân tộc dân chủ nhân dân.
Ngày 23/9/1945, thực dân Pháp quay trở lại xâm lược lần thứ 2 , chúng nổ súng đánh chiếm Sài Gòn, đánh sang Lào, Campuchia, và phát triển ra toàn cõi Đông Dương. Ba nước Việt Nam, Cam Pu Chia và Lào bước vào cuộc kháng chiến chống thực dân Pháp lần thứ hai. Ngày 20/01/1949, Quân đội Lào Ít-xa-la (tiền thân của Quân đội Nhân dân Lào) được thành lập tại vùng căn cứ Xiềng Khọ (Hủa Phăn) do đồng chí Cay-xỏn Phôm-vi-hản làm Tổng Chỉ huy. Mặc dù có quân đội nhưng tình hình cách mạng Lào lúc này hết sức khó khăn rất cần sự giúp đỡ của Đảng cộng sản Việt Nam.

Sau nhiều lần trao đổi thư từ qua lại của hai nhà lãnh đạo cao cấp hai nước Việt Nam và Lào, đến cuối tháng 11 năm 1949, nhận lời mời của Chủ tịch nước Việt Nam Dân chủ Cộng hòa, chủ tịch Hồ Chí Minh, Hoàng thân Xu Phan Nu Vông và các đồng chí cán bộ cách mạng cao cấp Lào đã rời căn cứ kháng chiến tại Sầm Nưa (thuộc Thượng Lào), vượt qua rãy Trường Sơn sang đến Việt Nam. Đoàn đại biểu Lào đã đi qua các căn cứ cách mạng của ta lúc bấy giờ tại các tỉnh Hà Tĩnh, Nghệ An, Hòa Bình,... Cuối tháng 12 năm 1949, sau gần một tháng băng rừng, vượt núi, Hoàng thân cùng với các cán bộ cách mạng Lào đến Hà Nội. Từ Hà Nội, Hoàng thân Xu Phan Nu Vông đã lên căn cứ địa Tân Trào, Tuyên Quang. Tại đây đã diễn ra cuộc gặp gỡ giữa hai vị lãnh đạo cao cấp Chủ tịch Hồ Chí Minh và Hoàng thân Xu Phan Nu Vông. Sau cuộc gặp gỡ lịch sử đó, Bác và các đồng chí cách mạng đã chọn xã Mĩ Bằng, huyện Yên Sơn, tỉnh Tuyên Quang làm địa bàn ở và hoạt động cho đoàn đại biểu cách mạng Lào. "Những năm 1950-1951, các thôn Làng Ngòi, Đá Bàn thuộc xã Mỹ Lâm, huyện Yên Sơn được chọn làm nơi ở và làm việc của chính phủ kháng chiến Lào, nơi tập trung những cán bộ cao cấp nhất của cách mạng Lào".

Nhận trách nhiệm khó khăn và cũng vinh dự, Tuyên Quang đã thực hiện tốt nhiệm vụ của Đảng và Bác giao phó, hoàn thành tốt nhiệm vụ quốc tế đối với nước bạn Lào.

\section{Chuẩn bị cơ sở vất chất tại đón đoàn đại biểu cách mạng Lào từ cuối 1949 đầu 1950}

Trong quá trình đoàn đại biểu Lào trên đường tời Việt Nam theo lời mời của Chủ tịch nước Hồ Chí Minh, để tạo điều kiện thuận lợi cho đoàn cán bộ Lào trong thời gian hoạt động tại Việt Nam. Đảng, Chính phủ đã chỉ đạo các cấp, các ngành và lãnh đạo tỉnh 
Tuyên Quang khẩn trương chuẩn bị mọi điều kiện chu đáo về cơ sở, vật chất, an ninh bảo vệ đoàn.

Cụ thể là "chỉ đạo một số ngành và địa phuoong Tuyên Quang khẩn truơng chuẩn bị co sở vật chất cho đoàn cán bộ cách mạng Lào" [5; Tr113]. Giao cho các đồng chí lãnh đạo tỉnh Tuyên Quang trực tiếp phụ trách việc chuẩn bị mọi điều kiện vật chất nhằm đảm bảo an toàn tuyệt đối và mọi điều kiện thuận lợi nhất cho sinh hoạt của đoàn đại biểu cách mạng Lào ở và hoạt động tại tỉnh.

Nhận được sự chỉ đạo của Đảng, Chính phủ, lãnh đạo tỉnh Tuyên Quang đã vạch ra kế hoạch bảo vệ an ninh, tạo mọi điều kiện thuận lợi cho đoàn cán bộ cách mạng cao cấp của Lào hoạt động trong thời gian ở Tuyên Quang. Sau khi đưa ra các phương án chọn địa bàn cho đoàn đại biểu cách mạng Lào ở và hoạt động tại Tuyên Quang, lãnh đạo tỉnh đã quyết định chọn xã Mĩ Bằng, huyện Yên Sơn làm nơi xây dựng đại bản doanh cho đoàn cán bộ cách mạng Lào sinh sống và hoạt động trong thời gian ở Việt Nam theo lời mời của Hồ Chủ Tịch.

Mỹ Bằng là một xã miền núi nằm ở phía Tây của huyện Yên Sơn. Nằm ở vị trí giáp ranh giữa ba tỉnh Tuyên Quang - Yên Bái - Phú Thọ, là cửa ngõ phía Tây Bắc của Tuyên Quang, nối liền giữa Tây Bắc và Việt Bắc, xã Mỹ Bằng, huyện Yên Sơn có vị trí chiến lược quan trọng. Từ đây có thể dễ dàng cơ động đi Chiêm Hóa, Tân Trào đặc biêt là trung tâm tỉnh lị Tuyên Quang. Xã Mỹ Bằng có "vùng rù̀ng đồi đan xen với các dãy núi chiếm phần lớn diện tích trong xã chủ yếu là nhưng đồi rùng bát úp trải dài xuống phía Nam của xã. Truớc đây là nhũng rùng cây rậm rạp thuận lợi cho việc đóng quân, trú ẩn và sản xuất của các công binh xuơơng, co quan đơn vị bộ độ $i$ " [3;tr3].

Nhân dân xã Mỹ Bằng có tinh thần yêu nước và cách nạng, năm 1943, cơ sở Việt Minh đầu tiên được thành lập tại đây; năm 1944, trụ sở Việt Minh được xây dựng tại sườn núi Là xã Mỹ Bằng. Với những yếu tố "thiên thời, địa lơi, nhân hòa", xã Mỹ Bằng, huyện Yên Sơn được chọn là nơi xây dựng đại bản doanh của Đoàn cán bộ cách mạng Lào trong kháng chiến chống thực dân Phằp xâm lược.

"Đầu 1950, đồng chí Nguyễn Công Bình - Chủ tịch tỉnh Tuyên Quang đã chỉ thị cho đồng chí Châu Sáng - Chủ tịch huyện Yên Son và các đồng chí lãnh đạo xã Mỹ Bằng chuẩn bị mọi mặt để đón đoàn cách mang Lào đến ở và hoạt động" [ 4; tr.11]. Các đồng chí Hoàng Văn Sinh - Bí thư chi bộ xã, Nguyễn Văn Cẩn - Chủ tịch Uỷ ban hành chính kháng chiến xã sau khi xem xét, chọn địa điểm đã cùng nhân dân dưới sự chỉ đạo của đồng chí Lê Dung - Thứ trưởng Bộ Giao thông sửa sang khu học xá quân dân miền núi ${ }^{1}$ tại gò Tre, xóm Thổ, Làng Ngòi làm nơi ở của đoàn. Nhân dân thôn làng Ngòi và bộ đội, dân quân du kích đã góp công, góp sức, nhanh tróng sửa đường, mở đường đi để đón đoàn.

Chuẩn bị cho Đại hội đại biểu toàn quốc Mặt trận Ítxala của nhân dân các bộ tộc Lào vào năm 1950 , quân và dân xã Mỹ Bằng dưới sự chỉ huy của chính quyền cách mạng, đã xây dựng khu căn cứ cách mạng Lào tại thôn Đá Bàn làm cơ sở cho đoàn đại biểu nước bạn tiến hành Đại hội. Để đảm bảo an toàn, bí mật, các ngôi nhà được làm trong khu rừng già, ẩn dưới những tán cây to. Toàn bộ nguyên vật liệu được khai thác tại địa phương.

Nhà ở, làm việc của Hoàng thân Xu Pha Nu Vông có chiều dài $7 \mathrm{~m}$, rộng $4 \mathrm{~m}$, cột được làm bàng gỗ rừng, vách bằng nứa đan nong đôi, mái lợp lá cọ, trong nhà có một số đồ dùng cá nhân do nhân dân địa phương cho mượn; cách nhà Hoàng thân khoảng $300 \mathrm{~m}$ là Hội trường có chiều dài $15 \mathrm{~m}$, rộng $6 \mathrm{~m}$, cột bằng gỗ, vách bằng nứa đan nong đôi, mái lợp lá cọ; trong hội trường có sân khấu đắp bằng đất, bàn ghế bằng tre nứa, chân bàn chôn xuống đất.

Bếp và nhà ăn cột bằng tre, vách bằng nứa đan nong đôi. mái lợp lá cọ. Hệ thống hầm hào được đào quanh nhà Hoàng thân, nối với hội trường, nhà ăn. Hào sâu $2 \mathrm{~m}$, rộng khoảng $80 \mathrm{~cm}$; hầm sâu $3 \mathrm{~m}$, rộng $2,5 \mathrm{~m}$, trong hầm có kê bàn ghế bằng tre. nứa, chân bàn chôn xuống đất, nóc hầm lát gỗ rừng, đương kính khoảng $20 \mathrm{~cm}$.

Cho đến khoảng tháng 5 năm 1950, mọi công việc chuẩn bị đón đoàn đại biểu cao cấp cách mạng Lào hoàn thành. Đồng chí Nguyễn Công Hoan, Chủ tịch tỉnh Tuyên Quang, đồng chí Chủ tịch huyện Yên Sơn và lãnh đạo xã Mỹ Bằng chuẩn bị đón đoàn. Tháng 6 năm 1950 Hoàng thân Xu Pha Nu vông, đồng chí Cay-xỏn Phôm-vi-hản, Khămtày Siphănđon, Phu Ma cùng các đồng chí cán bộ, bộ đội cách mạng Lào đã theo đường Hiên đến ở và làm việc tại thôn Làng Ngòi, xã Mỹ Bằng, huyện Yên Sơn, tỉnh Tuyên Quang.

\footnotetext{
${ }^{1}$ Đây là một trường học đào tạo con em các dân tộc trong vùng. Năm 1949 , trường sáp nhập với trường miền núi ở Liên khu $X$ và chuyển đi địa phương khác.
} 


\section{Công tác đảm bảo an ninh cho đoàn đại biểu cách mạng Lào tại Mĩ Bằng, Yên Sơn}

Trong thời gian đoàn đại biểu cách mạng Lào hoạt động tại Tuyên Quang, quân và dân Tuyên Quang, cụ thể là các đồng chí lãnh đạo huyện Yên Sơn cùng nhân dân khu Gò Tre, xóm Thổ, thôn Làng Ngòi, thôn Đá Bàn cùng toàn thể bà con nhân dân xã Mĩ Bằng đã tạo mọi điều kiện thuận lợi đảm bảo an ninh an toàn cho đoàn sinh hoạt, bảo vệ an toàn tuyệt đối trong thời gian đoàn sinh sống và hoạt động.

Trong thời gian đoàn đại biểu cán bộ cao cấp cách mạng Lào hoạt động tại Tuyên Quang, Đồng chí Nguyễn Công Bình - Chủ tịch tỉnh Tuyên Quang đã trực tiếp phụ trách công việc. Đồng chí Châu Sáng Chủ tịch huyện Yên Sơn là người chỉ đạo trực tiếp việc bảo vệ an ninh cho đoàn. Bảo vệ vòng trong cho hoàng thân $\mathrm{Xu}$ Phan $\mathrm{Nu}$ Vông, đồng chí Cay-xỏn Phôm-vi-hản là khoảng 200 chiến sĩ thuộc đại đội Champa Sắc của Lào. Bảo vệ an ninh vòng ngoài cho đoàn là một tiểu đội bộ đội quân đội nhân dân Việt Nam, phối hợp với dân quân, du kích xã Mĩ Bằng. Lực lượng Công an Tuyên Quang được giao nhiệm vụ bảo vệ vòng ngoài trên tuyến Quốc lộ $13 \mathrm{~A}$ (nay là Quốc lộ 37), bến phà Hiên và các xã xung quanh khu vực căn cứ cách mạng Lào. Đồng chí Nguyễn Văn Luân ${ }^{2}$, Trưởng ty Công An Tuyên Quang là người trực tiếp chỉ đạo công an Tuyên Quang phối hợp với bộ đội địa phương và dân quân du kích bảo vệ an toàn cho đoàn cán bộ cách mạng cao cấp của nước bạn Lào.

Công an Tuyên Quang đã vận động quần chúng nhân dân tích cực ủng hộ phong trào bảo vệ an ninh, trật tự, thực hiện chính sách "ba không", làm "tai, mắt" cung cấp cho công an và các lực lượng bảo vệ phát hiện kẻ gian, giữ bí mật an toàn cho khu cách mạng Lào. Công an Tuyên Quang cũng tăng cường huấn luyện nghiệp vụ cho công an xã, tăng cường kiểm soát chặt chẽ khu vực xã Mĩ Bằng và các khu vực lân cận. Việc kiểm soát nghiêm ngặt để phát hiện người lạ trong khu vực. Công an Tuyên Quang đã làm tốt công tác "phòng gian bảo mật", phát động nhân dân xây dựng thế trận bảo vệ an ninh nên đã đảm bảo an toàn cho đoàn cán bộ cách mạng cao cấp của nước bạn Lào trong thời gian hoạt động tại Tuyên Quang.

\footnotetext{
${ }^{2}$ Đồng chí Nguyễn Văn Luân (tức Lê Minh Cường còn có tên là Lê Danh Hỷ) giữ chức trưởng ty Công an Tuyên Quang từ năm 1947 đên 1957.
}

Sau khi chọn được nơi ở cho đoàn đại biểu cách mạng Lào, các đồng chí lãnh đạo huyện Yên Sơn được giao nhiệm vụ chính bảo vệ an toàn cho đoàn cán bộ cách mạng Lào, đặc biệt là hoàng thân $\mathrm{Xu}$ Phan Nu Vông. An ninh được kiểm soát chặt chẽ, “các điểm ngã ba, ngã tu vào xóm Ngòi nhu ở xóm Cây Quân, xóm Lũng, đương Thác Ông được đặt thêm các vọng gác để kiểm tra người lạ mặt" [3; $\operatorname{tr} 16]$.

Nhận được sự quan tâm, bảo vệ đặc biệt của nhân dân, chính quyền và công an tỉnh Tuyên Quang, năm 1950, tại xã Mĩ Bằng, huyện Yên Sơn đã diễn ra Đại hội đại biểu toàn quốc Mặt trận Ítxala của nhân dân các bộ tộc Lào. Hội nghị đã có nhiều quyết định to lớn quyết định đến vận mệnh của nước bạn Lào sau này. Hội nghị Itsxala cũng là bước chuẩn bị cho mọi thắng lợi của cuộc kháng chiến chống đế quốc Pháp Mĩ của nhân dân Lào. Sau khi Hội nghị toàn quốc lần thứ 3 của Đảng Cộng sản Đông Dương kết thúc, Chính phủ kháng chiến Lào, Mặt trận dân tộc thống nhất Lào cũng được thành lập (tháng 8 năm 1950, tại Tuyên Quang - Việt Nam) do Hoàng thân Xuphanuvong làm Chủ tịch kiêm Thủ tướng Chính phủ. Sự kiện này không chỉ đánh dấu sự trưởng thành của cuộc cách mạng Lào mà còn là kết quả của tình đoàn kết lâu dài giữa nhân dân Lào và nhân dân Việt Nam trong đó khẳng định vai trò quan trọng của Tuyên Quang với sự kiện lịch sử này.

Sau khi Đại hội Neo Lào Ítxala diễn ra thành công tại thôn Làng Ngòi, để đảm bảo cho an ninh và bí mật của đoàn, tháng 9 năm 1950, lực lượng an ninh của Tuyên Quang đã bố trí cho đoàn cán bộ cách mạng Lào và 200 chiến sĩ thuộc đại đội Champa Sắc của Lào vào ở tại thôm Đá Bàn, xã Mĩ Bằng. Trong khi chờ đợi dựng doanh trại cho đoàn ở bên kia suối phía Tây Bắc của thôn, đoàn cán bộ cách mạng Lào đã được bố trí ở các nhà dân tại thôn Đá Bàn. Cụ thể:

Hoàng thân Xu Phan $\mathrm{Nu}$ Vông ở nhà ông Lí An (tên thật là Lê Quang Trung). Ngôi nhà Hoàng thân ở là căn nhà sàn gỗ 4 gian, rộng rãi, thoáng mát được dựng trên lưng đồi. Tại ngôi nhà này, Bác Hồ đã đến thăm Hoàng thân và chụp ảnh với toàn thể gia đình ông Lí An. Ngôi nhà cũng là nơi diễn ra các cuộc họp của đoàn cán bộ cách mạng Lào trong thời gian đoàn ở Đá Bàn. 
Vừa thực hiện nhiệm vụ kháng chiến kiến quốc của dân tộc, quân dân Yên Sơn vừa thay mặt nhân dân cả nước làm tròn nghĩa vụ quốc tế cao cả đối với cách mạng Lào. Nhân dân các dân tộc trong vùng hết lòng giúp đỡ, bảo vệ, cung cấp lương thực thực phẩm; cho mượn mọi đồ dùng cần thiết như giường tủ, bàn ghế, mâm, bát, nồi, chậu... Hoàng Thân Xu Phan Nu Vông thường xuyên thăm hỏi bà con ở xung quanh khu vực doanh trại. Đoàn đã tổ chức ăn tết Nguyên đán cổ truyền của Việt Nam cùng nhân dân thôn Đá Bàn rất vui vẻ vào xuân Tân Mão năm $1951^{3}$ và đi chúc tết nhân dân địa phương, mừng tuổi các cháu thiếu nhi ở quanh thôn Đá Bàn. Các đồng chí cách mạng Lào đặc biệt là Hoàng thân và một số cán bộ nước Lào thường hay ra bãi đất trống phía Tây của thôn để đá bóng với bộ đội ta và thanh niên trong thôn. Bà con người dân tộc xã Mĩ Bằng, đặc biệt là đồng bào dân tộc Dao Quần trắng ở Đá Bàn rất quý mến Hoàng thân $\mathrm{Xu}$ Phan $\mathrm{Nu}$ Vông và đoàn cán bộ cách mạng Lào. Họ thường xuyên giúp đỡ các vật dụng cần thiết cho sinh hoạt hàng ngày và tặng gạo, rau, bắp, muối... Khi săn bắn được thú rừng hoặc những ngày tết, giỗ chạp đồng bào thường mang rượu, thịt, bún, bánh... đến biếu. Bà con nơi đây coi Hoàng thân $\mathrm{Xu}$ Phan $\mathrm{Nu}$ Vông và cán bộ Lào như anh em ruột thịt ${ }^{4}$.

\section{Kết luận}

Việc bảo đảm an toàn và tuyệt đối bí mật của lực lượng bộ đội, công an và nhân dân Yên Sơn đối với nơi ở và đóng quân của Chính phủ kháng chiến Lào trong những năm kháng chiến chống thực dân Pháp đã góp phần củng cố, tăng cường mối quan hệ tốt đẹp giữa hai nước, hai dân tộc Việt - Lào. Tuyên Quang là tỉnh có vai trò đặc biệt quan trọng, là nơi mối quan hệ Việt Nam - Lào được thiết lập và tạo cơ sở cho mọi liên minh hai nước sau này trong cuộc đấu tranh giành và bảo vệ độc lập dân tộc của hai quốc gia. Là khởi nguồn của mọi thắng lợi trong hai cuộc kháng chiến chống đế quốc Pháp và Mĩ. Tuyên Quang không chỉ là căn cứ cách mạng của nước ta mà còn là căn cứ cách mạng của nước bạn Lào trong thời kỳ chuẩn bị xây dựng chính phủ kháng chiến và lực lượng kháng chiến Lào.

\footnotetext{
${ }^{3}$ Buổi liên hoan được tổ chức tại đình đồi - nơi có hang Đá Bàn. Bàn ghế được làm bằng tre, nứa và kê thành những dãy dài.

${ }^{4}$ Ghi theo lời kể của ông Tướng Văn Linh, lão thành cách mạng sinh năm 1935 tại thôn Đá Bàn vào năm 2016. Gia đình ông đã vinh dự được các đồng chí cách mạng cao cấp Lào đến ở và hoạt động trong thời kỳ ở Tuyên Quang.
}

Với những đóng góp của Tuyên Quang với cuộc cách mạng Dân tộc dân chủ nhân dân Lào, với mối quan hệ ngoại giao Việt Nam - Lào trong lịch sử và thời kỳ hiện nay, nhân dân các dân tộc tỉnh Tuyen Quang đã vinh dự nhận được Huân chương Itsala hạng nhất của Đảng và Nhà nước Lào tặng. Đảng và chính quyền tỉnh Tuyên Quang luôn giữ gìn và phát huy truyền thống quý báu trong mối quan hệ hữu nghị giữa hai nước vốn tốt đẹp và bền vững. Tuyên Quang góp phần to lớn trong việc xây dựng mối quan hệ hữu nghị truyền thống, đoàn kết đặc biệt và hợp tác toàn diện giữa hai nước Việt Nam và Lào. Đó chính là mối quan hệ thủy chung, trong sáng hiếm có trên thế giới, là tài sản vô giá, nhân tố quan trọng trong sự phát triển của hai nước. Song song với quan hệ hợp tác toàn diện cấp nhà nước, các hình thức hợp tác và kết nghĩa giữa các địa phương của hai nước cũng không ngừng được mở rộng. Với vai trò nói trên, Tuyên Quang như một "địa chỉ đỏ” và là điểm đến tất yếu của những chuyến hành hương trở về cội nguồn của các đoàn đại biểu cao cấp Lào mỗi khi sang thăm Việt Nam.

\section{REFERENCES}

[1] Provincial Party Executive Committee Tuyen Quang (2001), History of Tuyen Quang province Party Committee, National Political Publishing House, Hanoi..

[2] Yen Son District Party Committee (2014) Yen Son District Party Committee History, Su That Publishing House, Hanoi.

[3] Party Committee of My Bang Commune (2017), History of the Party Committee of My Bang Commune (Period 1945-2015)

[4] Tuyen Quang Museum (2014), Profile 02 / LLBSDT-BT Lao revolutionary relic in Lang Ngoi village, Da Ban, My Bang commune, Yen Son, Tuyen Quang (2nd time).

[5] Quan Van Dung (2009), Tuyen Quang, the resistance capital, Ethnic Culture Publishing House, Hanoi.

[6] Archives of Tuyen Quang police (2005), Chronicle of the People's Police of Tuyen Quang 1945-1954

[7] Vietnamese Military History Institute Ministry of Defense (2014) History of Vietnamese Military Thought - Volume IV, National Political Publishing House. 


\section{TUYEN QUANG - A PLACE HAVING FAVOURABLE FACILITIES AND ENSURING SECURITY FOR THE LAO REVOLUTIONARY DELEGATION OPERATING IN MY BANG COMMUNE (YEN SON DISTRICT) FROM 1950 TO 1952)}

\begin{tabular}{l}
\hline Article info \\
\hline Recieved: \\
15/7/2020 \\
Accepted: \\
20/9/2020 \\
\hline
\end{tabular}

Keywords:

Tuyen Quang,

Resistance against the

French, revolutionary

base

\begin{abstract}
Tuyen Quang is a province in the mountainous area of northern Vietnam, bordering the provinces of Thai Nguyen, Phu Tho, Vinh Phuc, and Yen Bai. In the history of building and defending the country of the Vietnamese people, Tuyen Quang has always been considered a land with an important strategic position in politics, economy, defense and security. During the resistance war against the French colonialism, Tuyen Quang became the Party's main revolutionary base, in addition, was also a safe place for the Lao revolutionary delegation while living and operating in Vietnam.
\end{abstract}

